\title{
Pengaruh Terapi Relaksasi Zikir Dalam Menurunkan Nyeri Kepala Pada Pasien Hipertensi di Wilayah Kerja Upk Puskesmas Pal Tiga Kecamatan Pontianak Kota
}

(The Influence Of Dhikr Relaxation Therapy To Reducing Tension Headache Of Hypertension At Working Area Pal 3 Health Center Pontianak)

\author{
Erwin Setiawan *, Arina Nurfianti **, Hendra *** \\ *Mahasiswa Program Studi Keperawatan Universitas Tanjungpura \\ **Dosen Program Studi Keperawatan Universitas Tanjungpura,, \\ *** Dosen Program Studi Keperawatan Universitas Tanjungpura,
}

\begin{abstract}
ABSTRAK
Latar Belakang: Nyeri kepala merupakan keluhan sangat umum terjadi pada pasien dengan hipertensi. Terapi zikir merupakan salah satu intervensi yang dipercaya untuk menurunkan tingkat stress pasien dan meningkatkan kenyamanan, sehingga nyeri kepala pasien dapat berkurang. Belum ada pemberian terapi spiritual seperti terapi zikir yang dilakukan di area kerja Puskesmas Pal 3 Pontianak.

Tujuan: Mengetahui pengaruh terapi relaksasi zikir dalam menurunkan nyeri kepala pada pasien hipertensi di Puskesmas Pal 3 Pontianak

Metodologi: Menggunakan rancangan quasy-experimen dengan pre-post test controlled grup. Pengambilan sampel dilakukan dengan purposive sampling dengan sampel berjumlah 20 pada masing-masing kelompok. Analisis data dengan uji Wilcoxon dan Mann-Whitney dengan nilai $\mathrm{p} \leq 0,05$

Hasil: Karateristik responden rata-rata berusia 45-59 tahun (40.0\%) dan berjenis kelamin laki-laki (60.0\%). Tingkat intensitas nyeri pada kelompok intervensi didapatkan nilai $\mathrm{p}=$ 0,000 dengan nilai mean pretest $=2.90$ dan postest $=2.10$ juga kelompok kontrol di dapatkan nilai $\mathrm{p}=0,184$ dengan nilai mean pretest $=2.95$ dan postest $=3.00$. Pada perbandingan intensitas nyeri antara kelompok intervensi dan kontrol bernilai $\mathrm{p}=0,000$.

Kesimpulan: Terdapat perubahan intensitas nyeri kepala pasien hipertensi setelah diberikan terapi zikir pada kelompok intervensi dan tidak terdapat perubahan nyeri kepala pasien pada kelompok kontrol. Terdapat perbedaan antara perubahan intensitas nyeri kepala pasien hipertensi sehingga terapi zikir dapat dipertimbangkan untuk menjadi intervensi mandiri keperawatan dalam menangani masalah nyeri kepala pasien dengan hipertensi.
\end{abstract}

Kata kunci :Intensitas Nyeri, Hipertensi, Terapi Zzikir

Referensi : 70 (2009-2018) 


\begin{abstract}
Background: Headche is a very common complaint in patients with hypertension. Dhikr therapy is an intervention that is believed to reduce the patient's stress level and increase comfort, so that the patient's headche can be reduced. There has been no spiritual therapy such as dhikr therapy carried out in the working area of Pal 3 Community Health Center Pontianak.

Objective: Identifying the effect of dhikr theraphy toward pain level of tension headache patients in Pal 3 Health Center Pontianak.

Methodo: Quasy-experimental design with pre-post test controlled group. Sampling was done by purposive sampling amounted 20 in each group. Data were analyzed by wilcoxon and mann whitney with $p \leq 0,05$

Results: The average characteristics of respondents are aged 45-59 years (40.0\%) and male (60.0\%). The level of pain intensity in intervention group worth $p$-value $=0.000$ with the value of the mean pretest $=2.90$ and posttest $=2.10$ to control group $p$-value $=$ 0.184 with the value of the mean pretest $=2.95$ and posttest $=3.00$. In the pain intensity comparison between the intervention and control group p-value $=0.000$.

Conclusion: There are changes in pain quality of patients with tension headache after being given dhikr therapy in the intervention group and there is no change pain level of patients with tension headachepatients in control group. There is a difference between pain in the two groups that has been given dhikr theraphy that it can be considered to be independent nursing interventions in dealing with pain problem in patients with tension headache.
\end{abstract}

Keywords : Pain Intensity, Hypertension, Dhikr Therapy

References : 70 (2009-2018)

\section{PENDAHULUAN}

\section{Hipertensi merupakan}

salah satu masalah kesehatan

masyarakat yang semakin

serius terjadi baik di negara

maju maupun di negara

berkembang.

Hipertensididefinisikan sebagai

tekanan darah dengan nilai

yang melewati batas normal

yaitu lebih dari 140/90mmHg

yang dapat beresiko komplikasi

penyakit lain dan berujung kematian (Muhadi, 2016).

Hipertensi terbagi dalam dua tipe, yaitu hipertensi esensial atau primer, dan hipertensi sekunder atau yang disebabkan oleh penyakit lainnya. Komplikasi seperti gagal ginjal, gagal jantung maupun stroke adalah yang banyak terjadi pada penyakit hipertensi (Kowalak, 2011).

Banyak faktor yang dapat memengaruhi terjadinya 
hipertensi pada seseorang. Faktor-faktor yang bisa menyebabkan hipertensi dibagi menjadi dalam dua kategori, yaitu faktor resiko dapat dimodifikasi dan faktor resiko tidak dapat dimodifikasi (Arifin, 2016). Faktor risiko yang tidak dapat diubah pada hipertensi yaitu seperti genetik, jenis kelamin, ras dan proses penuaan yang terjadi, sedangkan faktor seperti pola makan, pola hidup dan stress yang dialami dapat dikaegorikan sebagai faktor pencetus hipertensi yang dapat diubah (South, Bijuni \& Malara, 2014, Arifin, 2016). Penderita hipertensi akan mengalami gejala-gejala seperti pandangan mata yang kabur, nyeri dada, kesusahan bernafas, takikardia, dan yang paling umum terjadi adalah nyeri kepala (Mazdeh dkk, 2016).

Data yang didapat dari Puskesmas Pal 3 Pontianak sendiri tercatat bahwa sebanyak 102 pasien hipertensi yang menderita nyeri kepala dengan total pasien diambil dan dirangkum selama 3 bulan terakhir yaitu sejak bulan Agustus 2018Oktober 2018.

Nyeri kepala yang terjadi pada pasien hipertensi adalah rasa yang tidak nyaman seperti tertusuk ataupun dipukul pada area kepala yang meliputi daerah wajah dan tengkuk leher dan merupakan keluhan sangat umum terjadi pada pasien dengan hipertensi (Perdossi, 2013). Nyeri kepala yang dialami oleh pasien dapat disebabkan oleh stress yang dirasakan, salah satunya yaitu stress dikarenakan tidak dapat menerima diri sendiri sebagai penderita tekanan darah tinggi (Kaplan, 2010). Marliani dan Tatan (2010) menyatakan bahwa nyeri kepala hipertensi juga dapat sering terjadi disebabkan aliran darah yang tidak maksimal sampai ke jaringan otak karena tekanan yang meningkat akibat 
penebalan dinding pembuluh darah.

$$
\text { Terdapat berbagai }
$$

macam terapi yang digunakan untuk mengatasi nyeri kepala yang dialami pasien, yaitu dengan terapi farmakologis dan non-farmakologis. Terapi relaksasi dapat dilakukan bermacam-macam yaitu dengan mengalihkan perhatian ke hal yang lain (distraction), ataupun dengan terapi relaksasi yang bersifat spiritual seperti terapi murottal dan terapi berzikir.Terapi berzikir dapat berfungsi sebagai metode psikoterapi yang akan menjadikan hati tentram, tenang dan damai, serta tidak mudah diombang-ambingkan oleh pengaruh lingkungan. Clinibel (Darokah \& Safaria, 2009, dalam Subandi, Widuri Nur Anggraieni, 2014) mengungkapkan bahwa pada setiap individu terdapat kebutuhan dasar spiritual (basic spiritual needs) yang harus dipenuhi. Zikir memiliki daya relaksasi yang dapat mengurangi ketegangan (stres) dan mendatangkan ketenangan jiwa Bacaan zikir mengandung makna yang sangat dalam dan dapat mengatasi nyeri kepala yang dialami oleh pasien (AzZumaro, 2011) dalam Subandi, Widuri Nur Anggraieni, 2014). Fenomena dan data awal di Puskesmas Pal 3 Pontianak didapatkan bahwa pada kategori semua umur, pasien yang menderita hipertensi selama 3 bulan terakhir sebanyak 102 orang. Peneliti juga melakukan wawancara kepada 5 orang penderita hipertensi yang sedang melakukan pengecekan di poli puskesmas. Sebanyak 4 dari 5 pasien mengatakan tidak memiliki terapi relaksasi khusus dalam menangani nyeri kepala yang dialami, sementara satu diantaranya mengaku terkadang mendengarkan murottal Al-Qur'an tetapi tidak dibarengi dengan zikir dan tidak dilakukan secara rutin. Pasien yang diwawancara tersebut menyatakan masih 
sering mengalami nyeri kepala terutama jika tekanan darah pasien lebih tinggi. Semua pasien yang diwawancara mengungkapkan bahwa ketika nyeri kepala datang menyerang, maka aktifitas yang sedang dijalankan oleh pasien cukup terganggu bahkan bisa terhenti sama sekali. Melihat fenomena tersebut, peneliti tertarik ingin mengetahui apakah ada pengaruh antara efektivitas terapi relaksasi zikir dalam menurunkan nyeri kepala pada pasien hipertensi di Puskesmas Pal 3 Pontianak

\section{METODE}

Penelitian ini menggunakan desain quasy experiment, yang bertujuan untuk mengetahui pengaruh atau efektivitas dari perlakuan yang diberikan pada satu kelompok yang terkontrol (Sugiyono, 2012). Rancangan yang digunakan adalah Non Equivalent Control Group Pretest-Posttest Design, dimana menggunakan satu kelompok perlakuan dan satu kelompok kontrol yang tidak dipilih dengan acak.

Partisipan pada penelitian ini adalah pasien terdiagnosa hipertensi yang menderita nyeri kepala, pemilihan sampel menggunakan purposive sampling dengan kriteria pasien merupakan pasien rawat jalan di Puskesmas Pal 3 Pontianak yang telah terdiagnosis hipertensi tipe I dan tipe II, pasien yang sadar serta memiliki pendengaran yang baik, dan pasien yang beragama Islam.

Hasil penelitian dianalisa menggunakan Uji Wilcoxon pada hasil kelompok kontrol dan kelompok intervensi, serta Uji Mann Whitney untuk melihat perbandingan posttest kelompok intervensi dan kelompok kontrol.

\section{HASIL DAN PEMBAHASAN}

Dari data yang terkumpul, didapatkan distribusi data umur dan jenis kelamin. 
Tabel. 1 Distribusi Data Responden

\begin{tabular}{|c|c|c|c|c|}
\hline \multirow[t]{2}{*}{ Variabel } & \multicolumn{2}{|c|}{ Intervensi $(n=20)$} & \multicolumn{2}{|c|}{ Kontrol $(\mathbf{n}=\mathbf{2 0})$} \\
\hline & $\mathbf{F}$ & $\%$ & $\mathbf{F}$ & $\%$ \\
\hline \multicolumn{5}{|l|}{ Usia } \\
\hline $29-44$ & 6 & 30.0 & 6 & 30.0 \\
\hline $45-59$ & 8 & 40.0 & 8 & 40.0 \\
\hline $60-74$ & 4 & 20.0 & 4 & 20.0 \\
\hline $75-90$ & 2 & 10.0 & 2 & 10.0 \\
\hline$>90$ & 0 & 0.00 & 0 & 0.00 \\
\hline \multicolumn{5}{|c|}{ Jenis Kelamin } \\
\hline Pria & 12 & 60.0 & 8 & 40.0 \\
\hline Wanita & 8 & 40.0 & 12 & 60.0 \\
\hline
\end{tabular}

Dari tabel diatas, dapat dilihat bahwa kisaran umur 45-59 tahun merupakan umur terbanyak pada kedua kelompok dan mayoritas jenis kelamin terbanyak adalah pria. Umur merupakan faktor dominan terhadap penyakit yang menyerang pembuluh darah. Umur yang semakin lanjut akan mempengaruhi penuaan pembuluh darah sehingga elastisitas yang dimiliki akan berkurang. Yuliani dan Iryani (2014) menyatakan bahwa insiden penyakit jantung koronoer (PJK) yaitu salah satunya gagal jantung meningkat pada umur pralansia dimulai dari kisaran $>45$ tahun.

Pada segi jenis kelamin, angka risiko pria terkena penyakit jantung lebih besar dibandingkan dengan wanita karena pria tidak memiliki hormon estrogen. Hormon estrogen berguna untuk menurunkan kolestrol jahat (LDL) dan meningkatkan kolestrol baik (HDL) sehingga dapat mencegah terjadinya pemgendapan di pembuluh darah yang dapat merujuk pada penurunan curah jantung. 
Tabel. 2 Pengaruh Skor Intensitas

Nyeri Kepala Sebelum dan

Sesudah Terapi Zikir

\begin{tabular}{llllll}
\hline Variabel & SD & Mean & Min & Max & P \\
\hline $\begin{array}{l}\text { Intervensi } \\
(\mathbf{n}=\mathbf{2 0})\end{array}$ & 0.308 & 2.90 & 3 & 6 & 0,000 \\
$\begin{array}{l}\text { Pretest } \\
\text { Posttest }\end{array}$ & 0.308 & 2.10 & 1 & 3 & \\
\hline $\begin{array}{l}\text { Kontrol } \\
(\mathbf{n = 2 0 )}\end{array}$ & 0.224 & 2.95 & 4 & 6 & 0,184 \\
$\begin{array}{l}\text { Pretest } \\
\text { Posttest }\end{array}$ & 0.000 & 3.00 & 4 & 6 & \\
\hline
\end{tabular}

Dari tabel diatas, didapatkan hasil bahwa ada pengaruh pemberian terapi zikir terhadap perubahan intensitas nyeri kepala pada kelompok intervensi $(p=0,000)$ dan tidak ada pengaruh apapun pada kelompok kontrol $\quad(p=0,184)$. Pasien yang diberikan terapi relaksasi zikir mengalami perubahan intensitas nyeri kepala yang signifikan. Hal ini dikarenakan pemberian terapi zikir akan meningkatkan kenyamanan pasien sehingga pasien merasa lebih rileks. Terapi relaksasi yang dilakukan oleh pasien kemudian dapat menenangkan pasien dan dapat membantu pernafasan lebih stabil. Hal ini akan membantu pengembangan paru dan mengurangit tekanan dari abdomen pada diagfragma pasien dengan hipertensi, sehingga pasien dapat bernafas lebih lega dan akan mengurangi ketidaknyamanan yang dirasakan.

Ancok dan Suroso (dalam Sucinindyasputeri, dkk (2017) dalam penelitiannya mendukung hal ini dengan menyatakan bahwa terapi spiritual seperti contohnya terapi zikir mengukuhkan aspek terapeutik berupa autosugesti pada pasien. Autosugesti tersebut memberikan efek suggest atau sugesti pada seseorang hingga ada upaya untuk membimbing diri sendiri menuju keyakinan atas perbuatan yang dilakukan yang berdampak pada ketenangan dan kondisi fisik yang lemah bisa ikut merasa lebih rileks. 
Tabel. 3 Perbandingan Skor Intensitas

Nyeri Kepala Antara Kelompok
Intervensi dan Kelompok

Kontrol

\begin{tabular}{lccc}
\hline Variabel & Mean & SD & P \\
\hline $\begin{array}{c}\text { Post-Test } \\
\text { Intervensi }\end{array}$ & 2.10 & 0.308 & \\
$\begin{array}{c}\text { Post-test } \\
\text { Kontrol }\end{array}$ & 3.00 & 0.000 & 0.000 \\
\hline
\end{tabular}

Dari tabel diatas dapat dilihat hasil bahwa terdapat perbedaan pemberian terapi zikir terhadap perubahan skor intensitas nyeri pasien hipertensi antara kelompok intervensi dan kelompok kontrol.

Pasien dengan hipertensi renyan mengalami penurunan curah jantung. Penurunan curah jantung akan menstimulasi sistem reninangiotensin-aldosteron (RAAS). RAAS yang aktif kemudian menyebabkan peningkatan energi jantung perfusi miokard berkurang dan akan berujung pada rentannya miokardium terhadap iskemia dan sirkulasi yang bergantung pada tonus simpatis. sehingga dapat menyebabkan kematian sel/apoptosis. Secara fisiologi, zikir yang dilakukan pasien akan mempengaruhi perubahan sel-sel

tubuh, medan elektromagnetis, dan memberikan efek relaksasi bagi tubuh yang sedang mengalami sakit seperti nyeri kepala karena zikir memberikan efek menenangkan. Hasil dari penelitian ini juga didukung oleh penelitian yang dilakukan oleh Prof Dr Fanani, SpKJ (dalam Kusumastuti, 2011) yang menyatakan bahwa pada dasarnya, metode ruqyah contohnya seperti memperdengarkan bacaan Al Quran, doa, dan memberikan terapi zikir dengan menguangi kalimat-kalimat suci Allah dapat menurunkan ketegangan otot hingga $60 \%$, sehingga pasien kembali merasakan relaksasi, tingkat stress yang dirasakan menurun dan nyeri yang dirasakan pun dapat mengalami penurunan. 


\section{KESIMPULAN DAN SARAN}

\section{Simpulan}

Berdasarkan hasil penelitian yang telah dilakukan, dapat ditarik kesimpulan yaitu sebagai berikut:

a. Terdapat perubahan intensitas nyeri kepala pasien hipertensi setelah diberikan terapi relaksasi zikir pada kelompok intervensi di area lingkup kerja Puskesmas Pal 3 Pontianak.

b. Tidak terdapat perubahan nyeri kepala pasien hipertensi pada kelompok kontrol di luang lingkup kerja Puskesmas Pal 3 Pontianak.

c. Terdapat perbedaan yang bermakna antara intensitas nyeri kepala kedua kelompok yang telah diberikan terapi relaksasi zikir.

\section{Saran}

a. Perlu ditambahkan variabel faktor yang mempengaruhi intensitas nyeri kepala dan observasi terhadap pasien harus dilakukan lebih menyeluruh. b. Dapat menjadi media pembelajaran bagi mahasiswa keperawatan tentang pengaruh terapi zikir dan perubahan intensitas nyeri kepala pasien hipertensi.

c. Membantu pasien untuk mendapatkan kenyamanan untuk mengurangi nyeri kepala yang dirasakan.

\section{Daftar Pustaka}

Agus Mustofa, Energi Zikir Alam Bawah Sadar: Serial ke-32 Diskusi Tasawuf Modern(Surabaya: Padma Press, 2011)

Ancok dan Suroso (2011) Psikologi Islami. Yogyakarta : Pustaka Pelajar

Andarmoyo, Sulistyo. 2013.Konsep dan Proses Keperawatan Nyeri.Yogyakarta: Ar-Ruzz Media.

Bahrami P, Zebardast H, Zibaei M. Prevalence and Characteristics of Headache in Khoramabad, Iran.

2012:327-332. 
Brunner \& Suddarth. 2010. Keperawatan Medikal Bedah Ed. 11. Jakarta : EGC

Carskadon, M.A., \& Dement, W.C. 2011. Monitoring and staging human sleep. In M.H. Kryger, T.Roth, \& W.C. Dement (Eds.), Principles and practice of sleep medicine, 5th edition, (pp 16-26). St.Louis: Elsevier Saunders.Clinical System Improvement, USA.

Department Of Health And Human Services, NIH Publication No. 04-5230,

Dharma, Kelana

Kusuma. 2011. Metodologi

Penelitian

Keperawatan. Jakarta: $\quad \mathrm{Cv}$ Trans info Media.

European Society of Cardiology (ESC). 2018. ESC/ESH Guidilines for The Management of Arterial Hypertension. Eur Heart J 33 Fanada, M., Muda, W. 2012. Perawat Dalam Penerapan Therapi Psikoreligius Untuk Menurunkan Tingkat Stress Pada Pasien Halusinasi
Pendengaran Di Rawat Inap Bangau Rumah Sakit Ernaldi Bahar Palembang 2012. Palembang : Badan DiklatProvinsi Sumatera Selatan.

Fousiah Dwi Astuti. 2013. Konsep Wirid Qur'ani (Studi Atas Kitab Al-Ma'surat Karya Hasan Al-Bana). Jurnal Penelitian Yogyakarta

Harisman .2012. Pengaruh terapi bekam basah terhadap nyeri kepala pada penderita hipertensi di Desa Gonilan Kartasura Sukoharjo . 2011. Perbedaan Efektivitas Terapi Bekam Dengan Akupuntur pada Nyeri Leher di Klinik Syariah Ar-Ridho

Klinis. Tangerang : Bina Rupa Aksara pp.1-8.

Karen EW, Jude B, Peter NB, Richie P. 2015. Tension Type Headache: A Life Course Review. IMedPubJournals

Kemenkes RI.Profil Kesehatan Indonesia tahun 2014.Jakarta Lionakis, N., et al. 2012. Hypertension in the elderly. World Journal of Cardiology, 
4, 135-147. Diakses pada

tanggal 14 November 2018

dari:

http://www.wjgnet.com/1949 $\underline{-8462 / f u l l / v 4 / 15 / 135 . h t m}$

Mahmudah, dkk 2015. Hubungan

Gaya Hidup Dan Pola Makan

Dengan Kejadian Hipertensi

Pada Lansia Di Kelurahan

Sawangan Baru Kota Depok

Tahun 2015. Jurnal

Biomedika. 8(2). 30 Juni

2017 (10:10)

Mozaffarian D, Benjamin EJ, Go AS,

et al; for the American Heart

Association Statistics

Committee and Stroke

Statistics Subcommittee.

Heart disease and stroke statistics-2015

Muhadi, 2016. JNE 8: Evidance

Based

GuidelinePenangananPasien

HipertensiDewasa. Vol 43 nomor 1 .

Munibari, Ezenwa, M. O. (2016).

Effect of relaxation therapy in reducing blood pressure ofessential hypertension patients.Journal

of

psychology in Africa
Notoatmodjo S. 2012. Metode

Penelitian Kesehatan. Jakarta:

Rineka Cipta

Notoatmodjo,S. 2012.Metodologi Penelitian Kesehatan.

Jakarta: Rineka Cipta.

Nuraini, B. 2015. Risk Fators of Hypertension. Faculty of Medicine, University of Lampung. vol. 4, No. 5, pp. 11

Nurlela. 2009. Pengajaran Agama dan Bahasa Arab, Jakarta: Bumi Aksara.

Nursalam. 2013. Metodologi Penelitian Ilmu Keperawatan: Pendekatan Praktis.Jakarta

SalembaMedika

Permatasari. 2016. Pengaruh Teknik Nafas Dalam dan Murrottal terhadap Skala Nyeri Sesudah Perawatan Luka pada Pasien Post Operasi. Jurnal FKIK $U M Y$

Prevention, Detection, Evaluation, and Treatment of High Blood Pressure. U.S.

Purwanto, S. 2012. Jurnal Relaksasi Zikir. Suhuf Vol. XV III. No. 01: Fakultas Psikologi. Universitas Muhammadiyah Surabaya 
Riset Kesehatan Dasar (Riskesdas).

2013. Badan Penelitian dan

PengembanganKesehatan

Kementerian RI tahun 2013.

Yuliani, F., Oenzil, F., \& Iryani, D.

2014. Hubungan Berbagai

Faktor Resiko Terhadap

Kejadian Penyakit Jantung

Koroner Pada Penderita

Hipertensi. Jurnal kesehatan

Andalas, 3 ( 